\title{
Improvements in tribological and anticorrosion performance of porous Ti-6Al-4V via PEO coating
}

\author{
C. Garcia-Cabezón ${ }^{1,2, *}$, M.L. Rodríguez-Méndez ${ }^{2,3}$, V. Amigó Borrás ${ }^{4}$, R. Bayón ${ }^{5}$, C. Salvo-Comino ${ }^{3}$, C. Garcia- \\ Hernandez $^{3}$, F.Martin-Pedrosa ${ }^{1,2}$ \\ ${ }^{1}$ Materials Engineering, E.I.I., Universidad de Valladolid, Valladolid 47011, Spain \\ ${ }^{2}$ BioecoUVA Research Institute, Universidad de Valladolid, Valladolid 47011, Spain \\ ${ }^{3}$ Group UVASENS, Escuela de Ingenierias Industriales, Universidad de Valladolid, Valladolid 47011, Spain \\ ${ }^{4}$ Instituto de Tecnología de Materials, Univesitat Politécnica de Valencia, Valencia 46022, Spain \\ ${ }^{5}$ Tribology Unit, Fundación IK4-Tekniker, Eibar 20600, Spain
}

Received: 10 March 2020 / Revised: 19 May 2020 / Accepted: 07 December 2020

(C) The author(s) 2020.

\begin{abstract}
Medical implants manufactured using biomaterial Ti-6Al-4V exhibit some disadvantages. Its higher elastic modulus than that of natural bone can cause stress shielding problems. This can be avoided using $\mathrm{Ti}-6 \mathrm{Al}-4 \mathrm{~V}$ with pores in the implant structure. However, poor corrosion and tribocorrosion behaviors are yielded because of the large area exposed to the medium. To mitigate both issues, coating technologies can be applied. The plasma electrolytic oxidation (PEO) process is a cost-effective process that has been used successfully in nonporous Ti alloys. In this study, two PEO coatings with different amounts of Ca/P are used. However, reports regarding their application in porous materials are scarce. The effects of PEO treatments on corrosion and tribocorrosion in $\mathrm{Ti}-6 \mathrm{Al}-4 \mathrm{~V}$ powder metallurgy are analyzed herein. The porous materials provide an efficient surface for PEO coatings, as demonstrated via scanning electron microscopy (SEM) and atomic force microscopy (AFM), and the porosity of the substrates improved the adherence of the coatings. The corrosion resistance measured via electrochemical impedance spectroscopy confirmed the beneficial effect of the coatings, particularly for long exposure time. The lower roughness, small pore size, and more compact film observed in the PEO-Ca/P sample resulted in favorable tribological and corrosion properties.
\end{abstract}

Keywords: Ti-based alloys; corrosion; tribocorrosion; surface modification

\section{Introduction}

Ti-6Al-4V alloy and pure Ti are the most preferred substances for biomedical applications such as orthopedic prostheses and dental implants [1]. Their lower Young's modulus, higher fatigue strength, better biocompatibility, and higher corrosion resistance compared with those of cobalt alloys or stainless steels justify their use as biomaterials.

Powder metallurgy (PM) is a technology capable of reducing the processing cost of Ti complex shape devices owing to its advantages such as lower material losses, fewer machining steps, better dimensional precision, and higher surface finish [2,3]. Although Ti alloys have a lower elastic modulus than other metallic metals, in the last decade, several failures in implants associated with stress shielding problems have been reported [4,5]. Components manufactured via PM contain residual porosity, which can reduce the elasticity modulus and improve cell adhesion [6]; however, it can worsen the mechanical properties and reduce the corrosion resistance [2]. A method to improve the mechanical properties and resistance to corrosion and tribocorrosion of porous Ti alloys is by

* Corresponding author: C. Garcia-Cabezón, E-mail: crigar@eii.uva.es 
modifying their surfaces.

The response of medical devices to the biological environment depends primarily on the surface characteristics of the material and often requires different properties of the surface and bulk. Hence, it is advisable to transform the surface of Ti alloys with a layer that improves biocompatibility [6]. Coating techniques for developing biologically active coatings such as laser surface treatment, ion implantation, electrodeposition [7], physical vapor deposition [8], and anodic oxidation via plasma electrolytic oxidation (PEO) have been used. The last technique has recently been used successfully in Ti alloys [9-12].

During PEO, metallic substrates are anodically polarized to high voltages above the dielectric breakdown, inducing the generation of short-lived plasma microdischarges on the substrate-surfaceelectrolyte interface [13-15]. By applying a positive voltage exceeding the dielectric breakdown of the oxide film, anodization occurs. During film growth, plasma microdischarges are continuously produced over the film's surface, accompanied by gas evolution and entrapment into the material as well as discharge channels created during the electrochemical process, inducing the formation of oxide films with a porous morphology and rough topography. In addition, oxide films produced via PEO are generally characterized by the presence of different crystallographic phases of $\mathrm{Ti}$ oxide such as rutile and anatase, which confer properties such as high hardness and consequently improved tribological properties as well as increased corrosion protection. The chemical compositions of the oxide films depend significantly on the electrolyte composition used to treat them and in general, and the films present hydrophilic properties [16-18]. The composition and microstructure of the metallic substrate selected for PEO are vital to the properties of the oxide films generated. In addition, parameters such as anodic voltage, current density applied, electrolyte composition, and temperature are crucial processing variables that significantly affect the properties of the grown PEO oxide films $[19,20]$.

In recent studies that investigate the effects of substrates, electrolyte compositions, and current modes on the properties of PEO films for pure Ti [21-23] and Ti-6Al-4V [18, 19, 24, 25] have been analyzed. Corrosion resistance was one of the most important factors analyzed, indicating that improved corrosion resistance in $\mathrm{NaCl}$ or PBS was primarily determined by the composition, thickness, and density of the inner layer. Meanwhile, the type and concentration of electrolyte species affected the corrosion resistance as well. Therefore, many researchers have focused on the role of various electrolytes with elements such as $\mathrm{Ca}, \mathrm{P}, \mathrm{Mg}, \mathrm{Si}, \mathrm{Zn}$, and $\mathrm{Mn}$ on $\mathrm{Ti}$ and $\mathrm{Ti}-6 \mathrm{Al}-4 \mathrm{~V}$. They demonstrated that the modified electrolytes provided higher resistance to corrosion and better osseointegration of dental implants [22, 26, 27].

$\mathrm{PEO}$ in porous Ti has been scarcely reported [28-31]. However, it demonstrates great potential in the surface engineering of porous materials for biomedical applications. Porosity may be advantageous to the growth of PEO coating and can result in enhanced corrosion resistance and mechanical/tribological properties. In this regard, Toptan et al. [31] recently investigated highly porous $\mathrm{Ti}$ samples and demonstrated that anodic oxidation treatment with $\mathrm{Ca}$ and $\mathrm{P}$ improved resistance to tribocorrosion in untreated samples, particularly for intermediate porosities. Therefore, this study was conducted to investigate the $\mathrm{PEO}$ of porous $\mathrm{Ti}-6 \mathrm{Al}-4 \mathrm{~V}$ and the resulting coatings from the electrochemical perspective.

It is noteworthy that $\mathrm{Ti}$ alloys present low wear properties [32]. This tribological behavior is characterized by heavy adhesive wear, high coefficient of friction, and poor abrasion resistance [33]. Furthermore, the contact of the biomaterial with saliva can induce corrosion. This electrochemical damage combined with the wear generated results in tribocorrosion, which is considered as one of the main causes of dental implant failures. The tribocorrosion behavior of Ti improved after PEO treatments; therefore, the PEO-Ti-treated samples exhibited higher corrosion resistance in artificial saliva (AS) than non-modified Ti [34]. In addition, better osseointegration or biocide properties can be obtained by adjusting the composition of the electrolyte [35]. Studies regarding the effect of PEO on the tribocorrosion behavior of porous materials in AS investigated via pin-on-disk wear testing have not been reported.

Hence, the main objective of this study is to investigate the effect of PEO coatings on porous Ti-6Al-4V samples produced via PM in AS using electrochemical testing, considering issues that may 
emerge when using them as dental implants. Two PEO electrolyte solutions with different $\mathrm{Ca} / \mathrm{P}$ ratios were analyzed. The corrosion resistance was evaluated via impedance measurements, considering the effect of immersion time in simulated body fluids. The tribocorrosion behavior was evaluated via a pin-ondisk wear test in an AS solution. To interpret the electrochemical results, the microstructure and surface aspects were considered.

\section{Experimental}

\subsection{Materials}

Disc specimens of $\mathrm{Ti}-6 \mathrm{Al}-4 \mathrm{~V}$ ( $20 \mathrm{~mm}$ in diameter and $6 \mathrm{~mm}$ in thickness) were obtained by blending elemental powders supplied by Se-Jong Materials Co., Ltd. The elemental powders were mixed in a tubule (electrical tumbler mixer, Bioengineering Inversina 2L, Germany) for $30 \mathrm{~min}$. The final composition of the powder mixture was $6.62 \% \mathrm{Al}, 4.55 \% \mathrm{~V}$, $0.55 \%$ maximum $\mathrm{O}, 0.3 \%$ maximum $\mathrm{N}, 0.5 \%$ maximum $\mathrm{H}$, and Ti balance. The powder mixture was uniaxially compacted at $600 \mathrm{MPa}$ using a cylindrical floating die. Sintering was performed in two stages. The first one involved a speed of $15^{\circ} \mathrm{C} / \mathrm{min}$ up to $780^{\circ} \mathrm{C}$ to obtain a homogeneous temperature, where allotropic transformation occurred in the entire mass; whereas the second one involved heating at a speed of $7^{\circ} \mathrm{C} / \mathrm{min}$ up to $1,250{ }^{\circ} \mathrm{C}$ for $3 \mathrm{~h}$. Subsequently, cooling was performed in the oven. The entire process was performed in a high vacuum $\left(<10^{-4} \mathrm{MPa}\right)$. No lubricant was added because of the high reactivity of $\mathrm{Ti}$. The porosity was investigated via image analysis.

A commercial keronite equipment $(20 \mathrm{~kW}$ AC power supply, KERONITE, KT 20-50, UK) was used to perform PEO treatments on disc samples made of Ti-6Al-4V alloy. An electrochemical cell with a capacity of $50 \mathrm{~L}$ was used, and the samples and stainless steel mesh were used as the anode and cathode, respectively. PEO was performed at $25 \mathrm{~A} / \mathrm{dm}^{2}$ for $10 \mathrm{~min}$.

Two different aqueous electrolytes were employed to compare the effect of the electrolyte composition. One of them was the commercial Keronite Electrolyte 1003-01 for $\mathrm{Ti}$ and a custom-developed electrolyte comprising $0.35 \mathrm{M}$ calcium acetate (calcium acetate hydrate, Scharlab, Spain) and $0.02 \mathrm{M} \beta$-glycerol phosphate ( $\beta$-glycerol phosphate disodium salt pentahydrate, Scharlab, Spain) as sources of $\mathrm{Ca}$ and $\mathrm{P}$, respectively. After the $\mathrm{PEO}$, the disks were rinsed in deionized water and labeled as PEO and PEO-Ca/P, respectively.

\subsection{Microstructural characterization}

The samples were investigated via optical metallography and scanning electron microscopy with energy dispersive X-ray spectroscopy (SEM/EDS) using an SEM instrument (QUANTA 200F, FEI). Kroll's reagent $\left(\mathrm{HNO}_{3}-\mathrm{HF}-\mathrm{H}_{2} \mathrm{O}\right)$ was used for $5 \mathrm{~s}$ of etching. Atomic force microscopy (AFM) images were recorded in a porous substrate and $\mathrm{PEO}$-coated samples at room temperature in a Cypher ES (Asylum Instruments, USA) operated in the tapping mode.

\subsection{Corrosion testing}

Electrochemical corrosion measurements were conducted using an impedance analyzer (Solartron SI 1260, Leicester, England) combined with an EG\&G potentiostat. A conventional three-electrode cell was used. The counter electrode was a graphite rod, and the reference electrode was an $\mathrm{Ag} \mid \mathrm{AgCl} / \mathrm{KCl}$ saturated electrode. A physiological AS solution $(2 \mathrm{~g} / \mathrm{L} \mathrm{NaCl}$, $2 \mathrm{~g} / \mathrm{L} \mathrm{KCl}, 3.95 \mathrm{~g} / \mathrm{L} \mathrm{CaCl}, 1.54 \mathrm{~g} / \mathrm{L} \mathrm{NaH} \mathrm{PO}_{4}, 5 \mathrm{~g} / \mathrm{L}$ urea, and $0.005 \mathrm{~g} / \mathrm{L}, \mathrm{Na}_{2} \mathrm{~S}$ ) at $37 \pm 1{ }^{\circ} \mathrm{C}$ was used as the electrolyte.

Electrochemical impedance spectroscopy (EIS) was performed, where impedance spectra were acquired in an AS solution at a frequency range from $1 \mathrm{MHz}$ to $0.01 \mathrm{~Hz}$ and a signal amplitude of $10 \mathrm{mV}$ at an open-circuit potential (OCP) before stabilization was performed for $1,800 \mathrm{~s}$ on the open circuit. Additionally, EIS analysis was performed on the samples after $15,30,45,60,75$, and 90 days of immersion in the AS solution at $37 \pm 1{ }^{\circ} \mathrm{C}$. Impedance data were processed using Zview software and fitted to equivalent circuits. The tests were repeated thrice.

\subsection{Tribocorrosion testing}

Pin-on-disk tribocorrosion tests were performed on a Microtest tribometer connected to an EG\&G potentiostat using MT4002 software. The disk was connected as the operating electrode; the counter-electrode comprised 
two graphite bars, and $\mathrm{Ag} / \mathrm{AgCl} \mathrm{KCl} 1 \mathrm{M}$ was used as the reference electrode. An electrochemical cell with the physiological AS solution at $37 \pm 1{ }^{\circ} \mathrm{C}$ was connected to the tribometer.

An alumina ball ( $3 \mathrm{~mm}$ in diameter and 1,500$1,650 \mathrm{HV}$ in Vickers hardness) was used as the counterbody. Prior to commencing the wear test, reference Ti-6Al-4V specimens were polished up to $1 \mu \mathrm{m}$ diamond and cleaned in an ultrasonic bath. The PEO samples were ultrasonically cleaned only.

OCP measurements were used as the tribocorrosion technique. The OCP was recorded against time throughout the pin-on-disk sliding tests. The coefficient of friction (COF), temperature, and track depth were continuously recorded. The evolution of the OCP was measured in the absence of loading, mechanical loading, and unloading. The potential was recorded for 1,800 s before starting the corrosion-wear sliding, which lasted for 3,600 s when a $4 \mathrm{~N}$ load was applied and $1,800 \mathrm{~s}$ after the load was removed. The disk was rotating at $60 \mathrm{rpm}$, whereas the sliding velocity and track radius were $0.1 \mathrm{~m} / \mathrm{s}$ and $2 \mathrm{~mm}$, respectively. All pin-on-disc tests were repeated thrice to ensure reproducibility. It is noteworthy that the aim of the tribocorrosion tests was not to simulate the real behavior of the materials as implants. Instead, it was performed to compare the different materials such that the most appropriate material can be identified.

After the wear tests, the general characteristics of the wear track and the determination of the wear volume loss were evaluated using profilometry. The wear rate was calculated using Eq. (1), and the volume loss of wear was calculated based on the appendix of American Society for Testing and Materials (ASTM) G99-05 standard [36]. Worn surfaces were observed via SEM to identify the wear mechanisms.

$$
\begin{aligned}
& \text { Wear rate }\left(\mathrm{mm}^{3} \cdot \mathrm{N}^{-1} \cdot \mathrm{m}^{-1}\right) \\
& =\frac{\text { Volume loss }\left(\mathrm{mm}^{3}\right)}{\text { Normal load }(\mathrm{N}) \times \text { Sliding distance }(\mathrm{m})}
\end{aligned}
$$

\section{Results and discussion}

\subsection{Microstructural characterization}

A typical duplex lamellar $\alpha+\beta$ structure was observed in the $\mathrm{Ti}-6 \mathrm{Al}-4 \mathrm{~V}$ sample sintered in a vacuum (Fig. 1(a)). The black areas shown correspond to pores. The average porosity of the samples was approximately $5.5 \mathrm{vol} \%$, the average area of the pores was $54 \mu^{2}$, and their average sphericity was 0.8 . The average grain area was $185 \mu \mathrm{m}^{2}$. All the parameters were determined using Buehler Omnimet image analysis.

The X-ray diffraction (XRD) patterns of the substrate sample, as shown in Fig. 1(b), confirmed that $\alpha$-Hexagonal close-Packed (HCP) was the main phase, and that a small amount of $\beta$-Body-centered cubic (BCC) phase retained at room temperature owing the presence of $\mathrm{V}$ as a beta stabilizer. Figure 1(c) depicts the SEM image of the substrate, showing the (a)

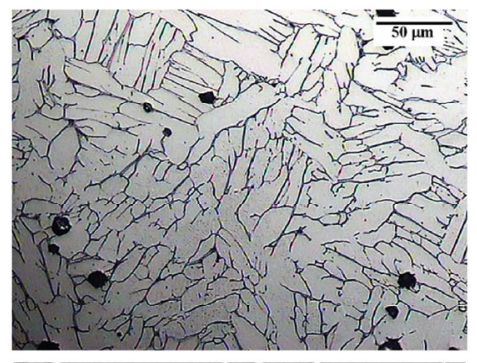

(b)

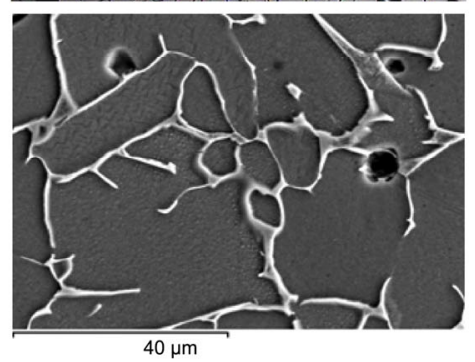

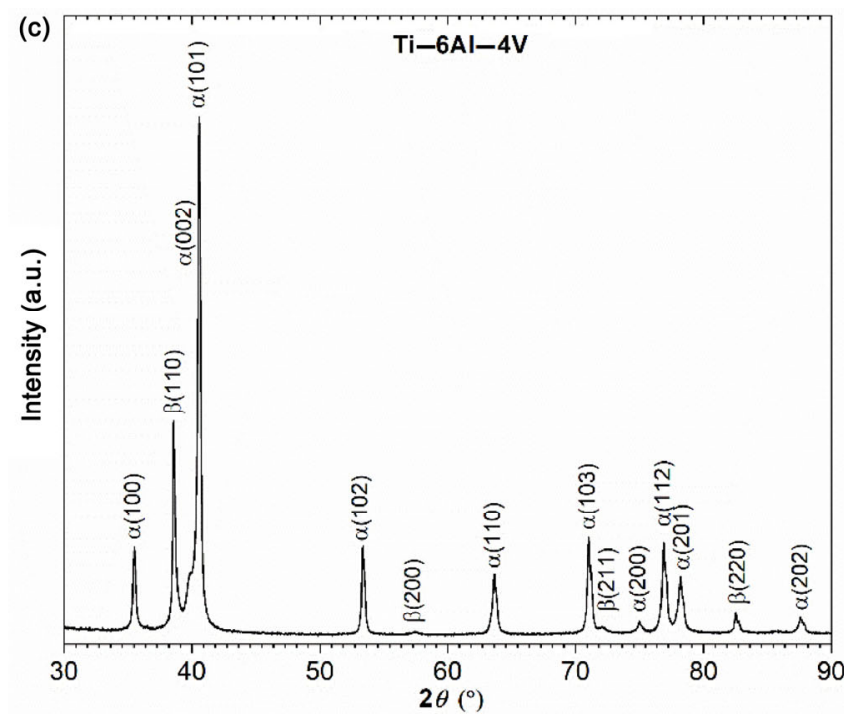

Fig. 1 (a) Light optical micrograph, (b) XRD diffractograms, and (c) SEM-BSE micrograph of porous Ti-6Al-4V. 
lamellar constituent that is identified as a combination of the $\alpha$-HCP phase (dark) and $\beta$-BCC phase (light), which retained in the form of thin plates. EDS confirmed that the $\beta$-BCC phase had a lower $\mathrm{Al} / \mathrm{V}$ ratio (0.27) than the $\alpha$-HCP phase (7.1).

The mechanical properties of the porous $\mathrm{Ti}-6 \mathrm{Al}-4 \mathrm{~V}$ substrate, such as the elasticity modulus and hardness, were measured. The microhardness, determined via the Vickers test using $0.3 \mathrm{~kg}$ for $10 \mathrm{~s}$ for the five samples, was $363.40 \pm 30.96$. The Vickers macrohardness ( $30 \mathrm{~kg}$ for $30 \mathrm{~s}$ ) was $310 \pm 19$. As expected, the macrohardness value was slightly lower than that owing to the effect of porosity. The elasticity modulus of the porous $\mathrm{Ti}$ alloy, determined via ultrasonic testing, was $114.76 \pm 1.66 \mathrm{GPa}$. The mechanical resistance and deformation of the substrate obtained via the three-point bending test were 1687.23 $\pm 90.2 \mathrm{MPa}$ and $4.63 \pm 0.29$, respectively.

Figures 2(a) and 2(b) show the surface morphologies of the coated samples corresponding to the PEO and $\mathrm{PEO}-\mathrm{Ca} / \mathrm{P}$ samples, respectively. Both samples exhibited a typical pancake shape structure with a regular and dispersed micropore network, although the PEO Ca/P sample showed a more uniform size and shape in the micropore structure. The cross section and thickness of the coated samples are depicted in Figs. 2(c) and 2(d), respectively, showing a more uniform and thinner inner layer as well as a more heterogeneous outer layer. The coating thickness was similar for both samples (approximately $16 \mu \mathrm{m}$ ). The most conspicuous difference between the two PEO samples was the chemical composition between the inner and outer layers, as shown in Table 1. For both samples, the amounts of metallic elements from the substrate, such as $\mathrm{Ti}, \mathrm{Al}$, and $\mathrm{V}$, were higher in the inner layer, whereas the amounts of $\mathrm{Ca}, \mathrm{P}$, and $\mathrm{Na}$ were higher in the outer layer. The main differences between the PEO and PEO-Ca/P samples were the absence of $\mathrm{V}$ in the $\mathrm{PEO}$ coating sample and the highest $[\mathrm{Ca}] /[\mathrm{P}]$ ratio in $\mathrm{PEO}-\mathrm{Ca} / \mathrm{P}$. The ratio was approximately 1.5 , which was similar to the case of natural bone in the PEO-Ca/P sample [27].

The above results reveal that both coatings have their own advantages. One of the main restrictions of the application of the alloy on bone implants is the release of toxic ions from the implant that can cause irritation to adjacent tissues. In this regard, the PEO
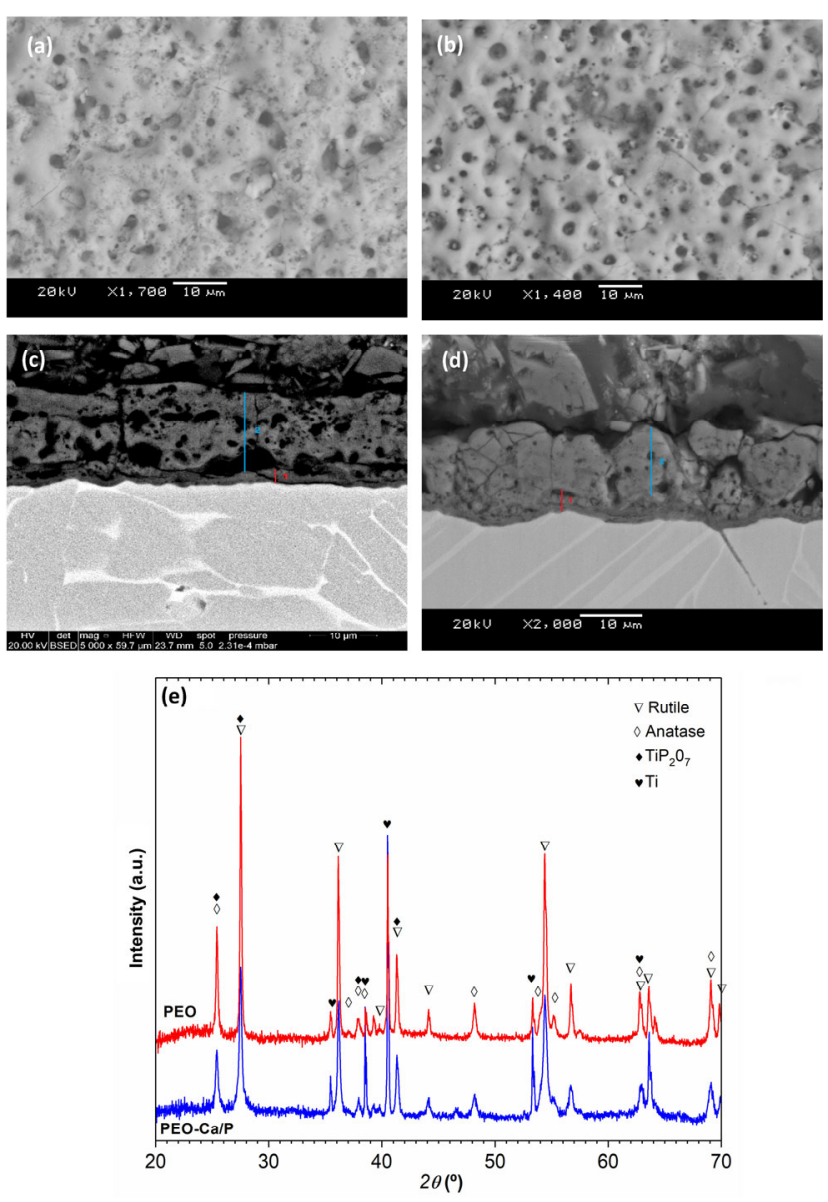

Fig. 2 SEM images of Ti-6Al-4V surfaces subjected to PEO (a) superficial PEO sample, (b) superficial $\mathrm{PEO}-\mathrm{Ca} / \mathrm{P}$ sample, (c) cross section of PEO sample, and (d) cross section of PEO-Ca/P sample; (e) XRD diffractograms of coated samples.

coating in which no vanadium is present may be more recommendable than the $\mathrm{PEO}-\mathrm{Ca} / \mathrm{P}$ coating [37]. In contrast, in the $\mathrm{PEO}-\mathrm{Ca} / \mathrm{P}$ coating, a higher amount of $\mathrm{Ca}$ and $\mathrm{P}$ has been detected, which would improve the biocompatibility of the titanium [38].

Figure 2(e) shows sharp peaks, indicating that the oxides formed contained crystalline and amorphous phases in addition to peaks corresponding to the substrate. The oxides formed in both samples were composed of rutile and anatase, the former being the dominant. It has been shown that anatase can improve the bioactivity, whereas rutile has a significantly higher hardness compared with anatase, affording improvement in the wear resistance [31, 34, 39]. Peaks of $\mathrm{Ti}, \mathrm{Na}$, and $\mathrm{Ca}$ complex phosphates were detected as well; however, they were difficult to be observed because some peaks coincided with those of the $\alpha-\mathrm{HCP}$ 
phase of Ti. The ratio of rutile to anatase was slightly higher in thePEO-Ca/P sample.

The average roughness was similar for both PEO samples; however, a clear increase was observed with respect to the reference sample from $0.05 \mu \mathrm{m}$ on the reference sample to 1.18 and $1.08 \mu \mathrm{m}$ for the samples oxidized for PEO and PEO-Ca/P specimens, respectively. Additionally, the AFM topographic images of the substrate, as shown in Fig. 3(a), showed the flat structure of the metal alloy. The AFM images of the PEO-coated samples showed a non-uniform topographic surface with islands, as shown in Figs. 3(b) and 3(c). In the case of PEO-Ca/P, as shown in Fig. 3(b), more uniform and small individual grains were observed, and the pores and cracks had lower depths than those of the PEO sample (Fig. 3(c)). The root mean square roughness of the PEO sample was approximately $306 \mathrm{~nm}$, whereas the roughness of the PEO-Ca/P sample was approximately $257 \mathrm{~nm}$. The individual grains of the PEO sample had an average

Table 1 EDS of PEO-treated Ti-6Al-4V alloy.

\begin{tabular}{cccccccccccc}
\hline Sample & Zone & $\begin{array}{c}\mathrm{Al} \\
(\mathrm{wt} \%)\end{array}$ & $\begin{array}{c}\mathrm{Ca} \\
(\mathrm{wt} \%)\end{array}$ & $\begin{array}{c}\mathrm{K} \\
(\mathrm{wt} \%)\end{array}$ & $\begin{array}{c}\mathrm{Na} \\
(\mathrm{wt} \%)\end{array}$ & $\begin{array}{c}\mathrm{P} \\
(\mathrm{wt} \%)\end{array}$ & $\begin{array}{c}\mathrm{Si} \\
(\mathrm{wt} \%)\end{array}$ & $\begin{array}{c}\mathrm{O} \\
(\mathrm{wt} \%)\end{array}$ & $\begin{array}{c}\mathrm{V} \\
(\mathrm{wt} \%)\end{array}$ & $\begin{array}{c}\mathrm{Ti} \\
(\mathrm{wt} \%)\end{array}$ \\
\hline \multirow{2}{*}{$\mathrm{PEO}$} & 1 & 2.91 & 0.66 & 0.16 & 0.33 & 4.68 & 0.46 & 45.62 & - & 45.44 \\
& 2 & 3.25 & 0.45 & 0.14 & 0.30 & 4.20 & 0.35 & 43.21 & - & 48.14 \\
\hline \multirow{2}{*}{$\mathrm{PEO}-\mathrm{Ca} / \mathrm{P}$} & 1 & 3.51 & 5.62 & 0.28 & 1.25 & 5.04 & 0.35 & 38.00 & 1.96 & 43.99 \\
& 2 & 3.82 & 5.93 & 0.29 & 1.22 & 3.99 & 0.21 & 37.51 & 2.02 & 44.76 \\
\hline
\end{tabular}
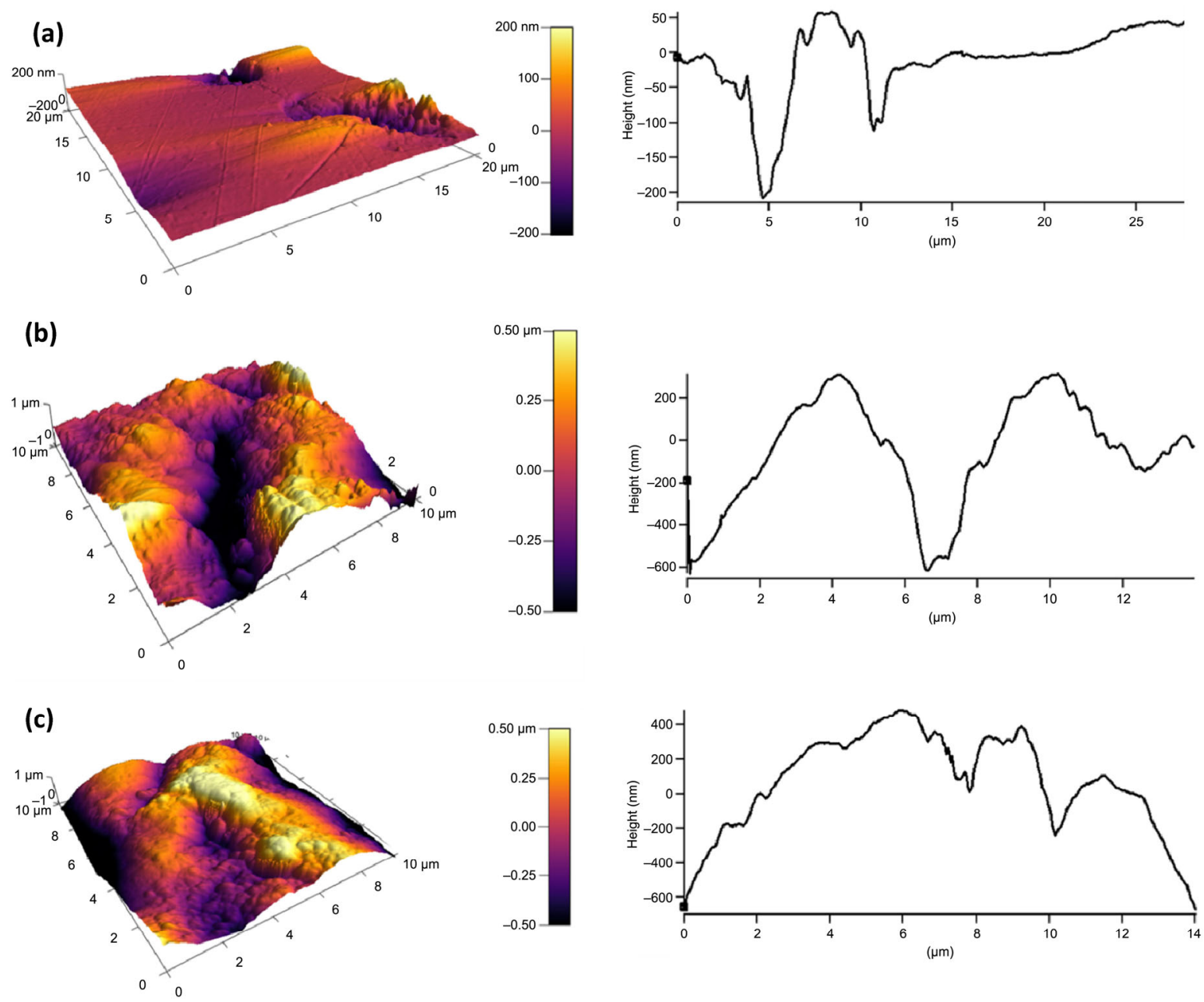

Fig. 3 (a) AFM topographic images of Ti-6A-14V substrate, (b) PEO coated sample, and (c) PEO-Ca/P-coated sample. 
diameter of $400-500 \mathrm{~nm}$, whereas the smallest grains measuring 200-300 nm were observed in the PEO-Ca/P sample. The line profile shows the importance of the pore depth and cracks. The depth and size of the pores of the PEO-Ca/P sample were smaller than those of the PEO sample. The lower roughness value, small grain size, small size, and number of pores in the PEO-Ca/P sample indicate that the coating was smoother and more compact with fewer pores compared with the PEO sample. This revealed that the electrolyte composition significantly affected the coating topography. The increased surface roughness achieved via these treatments can provide a stable bone-implant interface and promote the osseointegration of Ti implants [40].

\subsection{Corrosion behavior}

Impedance spectra can provide information regarding physicochemical processes occurring in the Ti-6Al- $4 \mathrm{~V}$ alloy and PEO-coated samples while they were corroding in the AS solution.

The Bode and Nyquist diagrams for the reference sample at different immersion time $(0,15,30,45,60$, 75 , and 90 days) in the simulated fluid (AS) at an OCP are presented in Fig. 4. The Nyquist curves revealed an incomplete capacitive loop. The semicircle increased in radius when the exposition time increased. Considering that a larger semicircle radius results in greater resistance to polarization in the material, it can be concluded that corrosion resistance increased during exposure. The impedance modulus was more than one order of magnitude higher for the sample measured after 90 days of exposure compared with that of the initial testing sample, indicating the better corrosion behavior of the former. The double layer and oxide capacitances were related to the dependence of the frequency on the phase angle. This increase in the corrosion resistance of non-modified Ti-6Al-4V with exposure time is attributed to the development of a reconstructed and thickened passive layer. This enhanced passive film is observed in conventional [21] and PM [5] Ti alloys.

The effect of immersion time in the aggressive solution for the PEO-coated samples differed from that for the noncoated sample but similar for both coatings. As shown in the Bode diagrams, the most significant changes occurred after 15 and 30 days of immersion, and the prolonged exposure time resulted in a slight increase and decrease in the impedance module without significant changes in the spectra. For the PEO-coated sample, the exposition in AS resulted in an increase in the impedance module, particularly at high and medium frequencies, as shown in Fig. 5(a); meanwhile, for the PEO-Ca/P-coated sample, the increase occurred in all frequency ranges, as shown in Fig. 5(b).

For comparison, Fig. 6 presents the Nyquist and Bode diagrams of the EIS results obtained for Ti-6Al-4V with and without PEO coating. Figure 6(a) shows the equivalent electric circuit proposed to interpret the EIS spectra of the uncoated and coated samples. Furthermore, Fig. 6 graphically shows the results of the fittings for 0 (Figs. $6(\mathrm{~b})-6(\mathrm{~d})$ ) and 90 days (Figs. 6(e)-6(g)) of immersion time in AS. The beneficial effect of the coating is clear before and after the immersion of the samples. Both PEO-coated samples showed a clear increase in the impedance module at all frequencies with the increase in the radius of
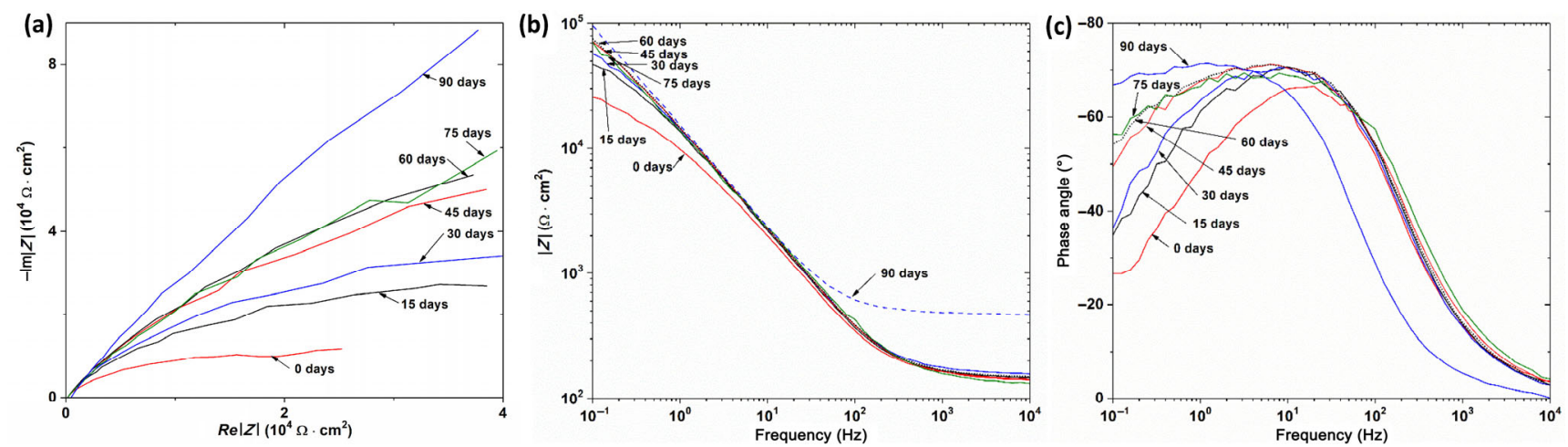

Fig. 4 Effect of immersion time in AS solution on EIS depicted in (a) Nyquist and (b, c) Bode plots of uncoated Ti-6Al-4V sample. 

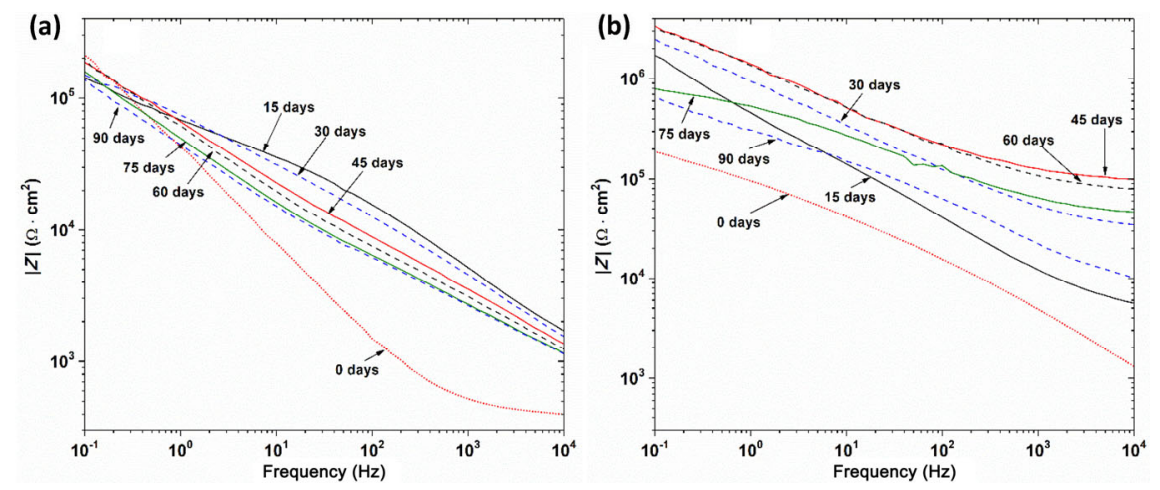

Fig. 5 Effect of immersion time in AS solution on Bode plots of (a) PEO-coated and (b) PEO-Ca/P-coated samples.
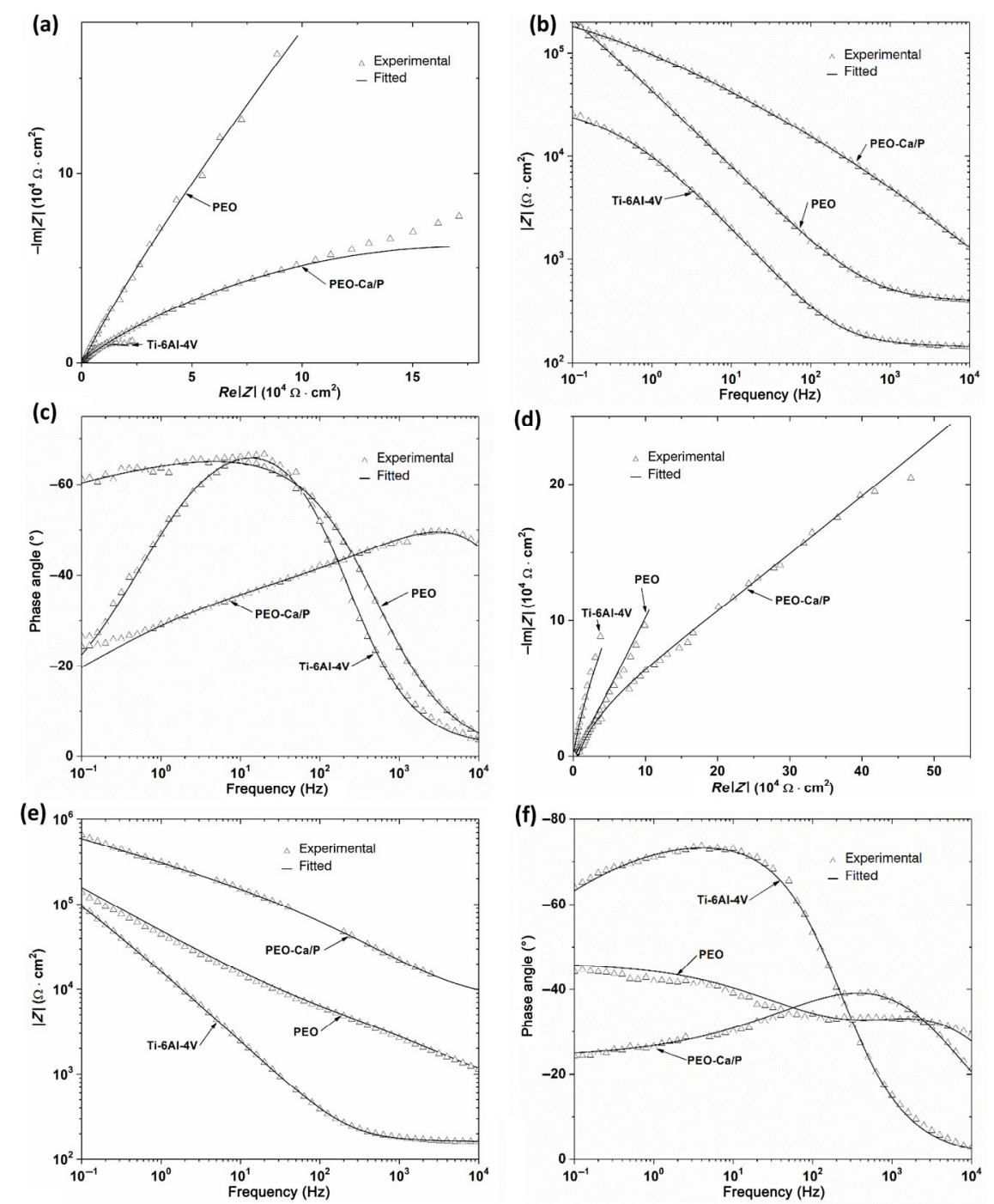

(g)

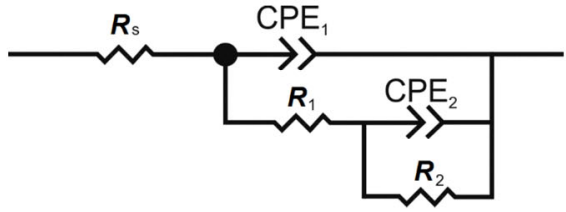

Fig. 6 Nyquist and Bode plots of Ti-6Al-4V, PEO, and PEO-Ca/P samples in AS solution after: (a-c) 0 days and (d-f) 90 days of immersion. (g) Results of fitting to equivalent electric circuit are included. 
the depressed circle shown in the Nyquist plot. The $\mathrm{PEO}-\mathrm{Ca} / \mathrm{P}$ sample showed the highest impedance module before and after immersion in AS. The Bode diagrams indicate that the uncoated Ti-6Al-4V presented a stable passive film on the surface, considering the capacitance and phase angle of $\sim 90^{\circ}$ in the low-middle frequency range. The PEO-coated sample appeared to generate the same pattern, but in the PEO-Ca/P-coated sample, the angle was reduced from $50^{\circ}$ to $20^{\circ}$ in the mid-high frequency range. The different corrosion behaviors with exposure time for the uncoated and coated samples may be related to the nature of the oxide film. The spontaneous passivating oxide present on the uncoated samples was polycrystalline and exhibited severe pitting and crevice corrosion [41], whereas surface treatment for forming an amorphous oxide resulted in excellent corrosion resistance [42].

Table 2 lists the parameters of the fitting. Chi-square values, $\chi^{2}$, were used to evaluate the quality of the fittings. The variable $\chi^{2}$ was on the order of $10^{-4}$. In the proposed model for the noncoated sample, $\mathrm{CPE}_{1}$ is the first time constant represented by the capacitance of the passive film in pore-free areas, and $R_{1}$ is the resistance of the porous oxide passive layer impregnated with the electrolyte. The electrolyte can penetrate through the pores of the passive layer. These defects resulted in the appearance of a second time constant related to the dissolution of the metal due to the formation of a nonprotective passive layer. Therefore, this second time constant may indicate that the substrate below the defective passive layer was subjected to a rapid dissolution process. The variables $\mathrm{CPE}_{2}$ and $R_{2}$ can be associated with the charge-transfer process through the nonprotected passive layer. These pores resulted in a double-layer capacitance $\left(\mathrm{CPE}_{2}\right)$ and a charge-transfer resistance
$\left(R_{2}\right)$. A similar equivalent electric circuit was used to analyze the corrosion mechanism of porous $\mathrm{Ti}-6 \mathrm{Al}-4 \mathrm{~V}$ alloy in physiological solutions [5] and other porous passive materials [43].

The porosity of the Ti-6Al-4V alloy resulted in a lower corrosion resistance value $\left(R_{1}+R_{2}\right)$ compared with those of solid alloys [44], resulting in a higher susceptibility of the porous materials to local corrosion. It was assumed that the relatively small pores in the cell walls favored the placement of electrolytes and oxygen depletion. This is vital to the stability and preservation of the $\mathrm{Ti}$ oxide layer; hence, the low resistance and high capacitance values were obtained from the uncoated sample.

For the coated samples, $\mathrm{CPE}_{1}$ and $R_{1}$ were related to the high frequency constant associated with the porous outer layer of the PEO coating, whereas $\mathrm{CPE}_{2}$ and $R_{2}$ were related to the medium-frequency time constant corresponding to the more compact inner layer of the PEO coating. An additional resistive Warburg element appeared in the PEO coating samples, reflecting a case of control by diffusion in the electrolyte or in a surface coating. This equivalent circuit has been used for nonporous PEO-coated samples [22].

The CPE element was used instead of the typical ideal capacitor, as indicated by the depressed circle observed in the Nyquist diagram. The impedance of this element is expressed as follows:

$$
Z_{\mathrm{CPE}}=\frac{1}{C(\mathrm{j} \omega)^{n}}
$$

where $\mathrm{j}$ is the imaginary unit. When $n=1$, the CPE is an ideal capacitor; when $n=0$, it describes an ideal resistor; and when $n=-1$, it is a pure inductance; furthermore, $C$ is a constant. As mentioned previously,

Table 2 EIS equivalent circuit parameters of reference and coated samples.

\begin{tabular}{ccccccccc}
\hline Sample & $\begin{array}{c}\text { Time } \\
(\mathrm{d})\end{array}$ & $\begin{array}{c}\mathrm{CPE}_{1}-\mathrm{C} \\
\left(10^{-6} \mathrm{~s}^{n} \cdot \Omega^{-1} \cdot \mathrm{cm}^{-2}\right)\end{array}$ & $\mathrm{CPE}_{1}-n$ & $\begin{array}{c}R_{1} \\
\left(\Omega \cdot \mathrm{cm}^{-2}\right)\end{array}$ & $\begin{array}{c}\mathrm{CPEC}_{2}-\mathrm{C}^{-2} \\
\left(10^{-6} \mathrm{~s}^{\mathrm{n}} \cdot \Omega^{-1} \cdot \mathrm{cm}^{-2}\right)\end{array}$ & $\begin{array}{c}\mathrm{CPE}_{2}-n \\
R_{2}\end{array}$ & $\begin{array}{c}\chi^{2} \\
\left(\Omega \cdot \mathrm{cm}^{-2}\right)\end{array}$ \\
\hline \multirow{2}{*}{ Ti-6Al-4V } & 0 & 20.1 & 0.29 & 152.1 & 13.2 & 0.86 & 46,985 \\
& 90 & 4.71 & 0.39 & 80.9 & 11.0 & 0.87 & $5.92 \times 10^{15}$ & 8.3 \\
\hline \multirow{2}{*}{ PEO } & 0 & 5.67 & 0.76 & 8,405 & 0.004 & 0.79 & 730,540 & 9 \\
& 90 & 1.01 & 0.65 & 4,202 & 7.22 & 0.50 & $8.76 \times 10^{19}$ & 2 \\
\hline \multirow{2}{*}{ PEO-Ca/P } & 0 & 36.6 & 0.42 & 2,504 & 0.04 & 0.86 & 35469 & 2 \\
& 90 & 1.89 & 0.27 & 5.886 & 0.07 & 0.72 & $7.15 \times 10^{19}$ \\
\hline
\end{tabular}


the flattening of the circle in the Nyquist diagram is indicative of non-ideal behavior. This behavior may be associated with superficial heterogeneities such as the surface roughness, impurities, dislocations, and pores in the passive film. These microscopic heterogeneities at the meta-electrolyte interface indicate that $C$ is not a real capacitance, and its units are $\mathrm{s}^{n} \cdot \Omega^{-1} \cdot \mathrm{cm}^{-2}$ instead of $\mathrm{F} \mathrm{s}^{n-1} \cdot \mathrm{cm}^{-2}$.

Table 2 shows that the resistance of the porous passive oxide layer $\left(R_{1}\right)$ is extremely low for all samples. In the coated samples, this implies that the outer layer is porous with some cracks; hence, electrolyte penetration is possible. It is noteworthy that $R_{2}$ is always higher than $R_{1}$. For $R_{2}$, the effect of the coating was more relevant. This might indicate that the inner layer provided the greatest resistance to corrosion, whereas the outer layer, which was the most porous and cracked, contributed scarcely to the corrosion protection of the substrate. Furthermore, the values of the CPE parameters differed for these layers; $\mathrm{CPE}_{2}-n$ was the highest for the inner layer, suggesting that this sublayer was more compact that the outer layer. The sum of $R_{1}, R_{2}$, and $W-R$ was established as the polarization resistance, which is associated with the corrosion resistance. The PEO-Ca/P sample showed the highest resistant before immersion testing; this might be attributed to the smoother, more compact, and less porous layer, as shown by the AFM topographic images of this coated sample.

Furthermore, Table 2 shows the important changes after 90 days of exposure. The fitting data suggested that exposure to AS confirmed the improvement in corrosion resistance for the noncoated sample. The $R_{2}$ and $W-R$ variables of the inner layer formed in the PEO samples showed an increase, which was higher in the PEO sample than in the PEO-Ca/P sample; hence, both samples showed similar polarization resistance. The lowest $\mathrm{CPE}_{2}-\mathrm{C}$ values were reflected by the $\mathrm{PEO}-\mathrm{Ca} / \mathrm{P}$-coated samples, indicating that prolonged exposure increased corrosion resistance. The results suggest that a highly resistant and passive film may develop in the pores of the coating filled with the AS solution, resulting in a slight decrease in the CPE-C values and an increase in the $R$ values during 90 days of exposure to the AS solution. This phenomenon was observed in other porous coatings on Ti alloys [45]. Meanwhile, the differences between the two coatings is attributable to the surface of the coating, which can serve as a nucleation and growth site for new hydroxyapatites for the samples coated with PEO-Ca/P $[46,47]$.

In the present study, the behavior of PEO coatings formed on porous $\mathrm{Ti}$ alloys after long-term exposure was satisfactory, unlike other literature data describing the behavior of the PEO layer on nonporous pure Ti and $\mathrm{Ti}$ alloys when the corrosion resistance decreased for long-term exposures [21]. No pitting, cracks, or other defects appeared on the surface after the immersion tests, indicating good agreement with the impedance spectroscopic analysis. The main advantages of anodic oxidation are improved adhesion and bonding as well as increased resistance against corrosion and wear [48]. In the case of porous materials, the reaction of the pores of the electrodes in the electrolyte can facilitate the growth and anchorage of the oxide layer. Consequently, strong protection against corrosion can be achieved for long periods of exposure. In addition, this will reduce the exposed area and the formation of galvanic cells, which are main issues of materials created via PM.

\subsection{Tribocorrosion behavior}

The changes in the OCP with time for the reference and PEO-coated samples were monitored with respect to the immersion time before $(1,800 \mathrm{~s})$, during $(3,600 \mathrm{~s})$, and after $(1,800 \mathrm{~s})$ sliding, as shown in Figs. 7(a) and $7(b)$.

Before sliding, the OCP of the reference sample increased with time, indicating the formation of a passive film on the alloy. An abrupt decrease in potential was observed after the initiation of sliding, and it remained almost constant (at approximately $\left.-0.74 \mathrm{~V}_{\mathrm{Ag} / \mathrm{AgCl}}\right)$ until the end of testing. This is the typical tribocorrosion behavior of passivated Ti alloys [5, 26]. The potential decrease is an indication of depassivation on the surface and the exposure of a new active surface to the electrolyte. The potential recorded during the abovementioned sliding conditions was the result of galvanic coupling between passive (unworn) and active areas (wear track). After sliding, the OCP increased immediately to high positive values, indicating that the worn area was repassivated. 

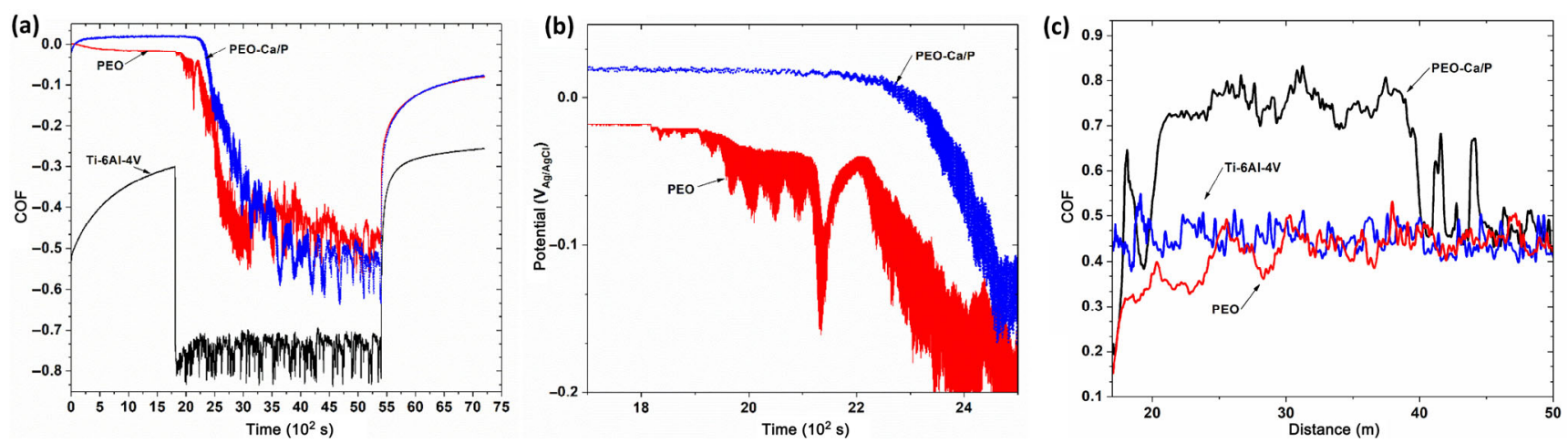

Fig. 7 (a, b) OCP and (c) COF evolution during sliding process for Ti-6Al-4V as well as $\mathrm{PEO}$ and $\mathrm{PEO}-\mathrm{Ca} / \mathrm{P}$ samples.

The potentials of the PEO-coated sample during the tribocorrosion tests differed completely. Before sliding, the OCP values in both coatings were more positive than those of the uncoated Ti alloy, owing to the insulating properties of the oxide Ti coating. This shift to more noble potentials was observed in porous Ti [31]. The OCP values did not undergo a sharp drop during the first few minutes of testing after the sliding process began, indicating that the coating was not affected by the sliding. The time incurred by the PEO-Ca/P sample was higher. Subsequently, the OCP decreased with a gentle slope for approximately $3,000 \mathrm{~s}$, indicative of the partial elimination and/or removal of the anodic coating. Subsequently, the potential increased and decreased to an average value of approximately $-0.5 \mathrm{~V}_{\mathrm{Ag} / \mathrm{AgCl}}$ and remained at that value until the end of the test. These fluctuations in the OCP might be related to the dynamic equilibrium between re-passivation by electrochemical oxidation and de-passivation by mechanical interactions in the wear track $[49,50]$. After the sliding, the OCP evolved to the highest values and finally reached values slightly lower than those recorded prior to the sliding. This might be associated with the formation of new films in the worn surfaces, in which values different from the initial values were recorded. After the test, it was observed that part of the coating was removed and redeposited, generating a protective tribolayer as a result of the adhesive wear. This caused the potential to reach high values again. This tribolayer originated from the compacted oxide debris, which filled the pores of the layer. The chemical composition of the worn areas was analyzed via EDS. In addition to $\mathrm{O}$ and $\mathrm{Ti}$, elements from coatings such as $\mathrm{Ca}, \mathrm{P}$, and
$\mathrm{K}$ were detected. It was confirmed that the coating served as a protective layer against tribocorrosion conditions. A similar tribocorrosion behavior was observed for PEO coatings on a nonporous Ti-6Al-4V substrate [51]. For porous $\mathrm{Ti}$, the behavior was a function of the porosity degree. For extremely porous samples, the potential barely changed during sliding and indicated negative values during the entire test [31].

The evolution of the COF with the sliding time for the noncoated and PEO-coated samples is shown in Fig. 7(c). In the reference sample, the COF increased immediately after the start of the sliding and fluctuated around a mean value of 0.45 , similar to the COF of wrought Ti-6Al-4V samples typically used in knee joint replacement [44]. For the PEO sample, the COF increased progressively as the OCP decreased, and after approximately $30 \mathrm{~min}$, the mean COF value was similar to that of the reference sample. The COF values of the PEO-Ca/P sample were higher than those of the PEO sample for most of the sliding conditions. This is attributable to some surface features (composition, crystalline structure, and hardness) between the two coated samples. It was observed that the COF of the two coatings differed significantly. For the PEO-Ca/P coating, the COF was clearly higher during most of the test; this is attributable to the higher roughness and hardness of the $\mathrm{Ca} / \mathrm{P}$-enriched $\mathrm{TiO}_{2}$ layer contributed by its ceramic nature, compared with those of Ti-6Al-4V [35]. The microhardness of the Ti-6Al-4V alloy was approximately $365 \mathrm{HV}$, whereas the hardness of the $\mathrm{TiO}_{2}$ coatings developed via PEO technology was highly variable and ranged from 400 to $600 \mathrm{HV}$. In addition, the COF of the PEO-Ca/P sample showed 
significant fluctuations related to the presence of detritus that detached and redeposited on the test track, creating a new tribolayer. Similar COF values were obtained for conventional nonporous PEO-Ti samples containing $\mathrm{Ca}$ and $\mathrm{P}$, with a value of approximately 0.7 [50]. For the PEO coating, the COF data were similar to those of the substrate, indicating that the coating was removed at the initial stage of the test and the detritus was ejected and not trapped; therefore, the COF was similar to that of the base metal. Finally, the COF decreased with no significant difference between the coated and noncoated samples.

Figure 8 shows the SEM micrographs of the wear track after the tribocorrosion test was performed on the reference and PEO-coated specimens. As expected, a combination of wear mechanisms was visible in the wear track of the Ti-6Al-4V reference sample. Scratches and grooves aligned in the direction of the pin movement indicated the occurrence of abrasion. Furthermore, ductile behavior and plastic deformation was observed; finally, during the sliding of debris, particles were removed from the surface and became entrapped in the wear, resulting in third-body wear. The wear track on the PEO-coated samples was characterized by a width that was smaller than that of the reference sample. The wear track on the PEO samples was characterized by a central zone, where wear marks appeared to be aligned in the direction of the pin movement, indicating that the anodic film can be removed when sliding and abrasive wear occurred in the substrate. This central area was higher for the PEO sample. On the side of the wear tracks of the PEO-coated samples, it was observed that part of the anodic film that was detached during sliding was subsequently re-deposited as a result of adhesive wear. Adhesive wear has been referenced as the main wear mechanism in nonporous PEO-treated samples $[34,35]$; however, in our case, as a consequence of aggressive tribocorrosion test conditions, i.e., high loads and far distances applied, the anodic film in the innermost part of the PEO-treated sample had detached. A similar behavior was observed in the PEO-treated solid Ti alloy Ti-6Al-4V [52] in alkaline solution [53] and in the simulated body fluid. The coating improved the anti-wear performance of the alloy and extended the sliding distance from $15 \mathrm{~m}$ in dry conditions to $100 \mathrm{~m}$ without significant wear [54]. Laurindo et al. [54] investigated the effect of PEO voltage on a solid substrate and the effect of post-heating treatment temperature on the wear resistance of PEO layers. They discovered that a higher applied voltage and a higher heat treatment temperature resulted in a higher wear resistance, owing to the increase in the crystalline rutile phase in the oxide layer, i.e., the main phase in the oxide film for porous substrates.

The wear resistance was calculated from the volume loss values for the reference $\left(5.06 \times 10^{-3} \pm 2 \times\right.$ $\left.10^{-4} \mathrm{~mm}^{3} \cdot \mathrm{N}^{-1} \cdot \mathrm{m}^{-1}\right)$ PEO $\left(4.55 \times 10^{-3} \pm 2.3 \times 10^{-4}\right.$ $\left.\mathrm{mm}^{3} \cdot \mathrm{N}^{-1} \cdot \mathrm{m}^{-1}\right)$ and PEO-Ca/P $\left(3.06 \times 10^{-3} \pm 1.2 \times 10^{-4}\right.$ $\mathrm{mm}^{3} \cdot \mathrm{N}^{-1} \cdot \mathrm{m}^{-1}$ ) samples. Therefore, the oxides of the PEO samples provided protection by reducing the damage, particularly that caused by adhesive wear; however, clear differences were observed between the coated samples. The PEO sample presented worn surfaces similar to those of the PEO-Ca/P sample (Figs. 8(b) and 8(c)), but the compacted oxide debris was not as intense as the $\mathrm{PEO}-\mathrm{Ca} / \mathrm{P}$ sample; this may be due to the ejection of some of the oxide debris from the worn area as a result of its higher brittleness. They can move on the sliding surface, resulting in third-body wear [39], whose rate was significantly higher. The lowest wear rate was shown by the

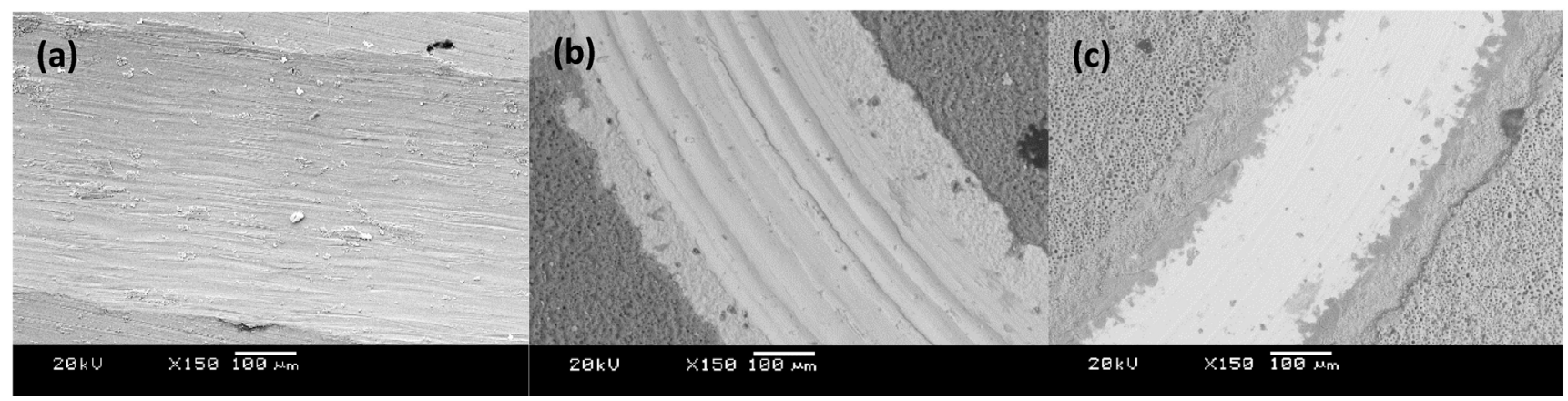

Fig. 8 SEM of wear tracks on (a) untreated Ti-6Al-4V, (b) PEO, and (c) treated PEO-Ca/P samples after sliding tests. 
$\mathrm{PEO}-\mathrm{Ca} / \mathrm{P}$ coating, indicating its higher resistance to tribocorrosion. This is attributable to the smoother, more compact, and less porous coating compared with the PEO sample, as observed in the topography via AFM. In addition, it may be attributed to the difference in the composition of the anodic coating (higher amount of sodium/calcium phosphate and higher rutile to anatase ratio for $\mathrm{PEO}-\mathrm{Ca} / \mathrm{P}$ coating).

It is known that the Ti-6Al4-V alloy without a coating or surface treatment is not suitable for bearing surface applications such as hip heads and femoral knees [48]; furthermore, it is unsuitable for orthopedic applications $[55,56]$ because of its high elastic modulus, which causes inadequate load transfer from the implant to the adjacent bone, resulting in its degradation over time. The oxidation treatments of PM materials investigated in this study may be implemented such that these biphasic alloys can be used in medical applications, considering the fact that elements $\mathrm{V}$ and $\mathrm{Al}$ that are toxic to the human body appear in extremely low proportions on the surface of the developed coatings. Therefore, in future studies, these treatments will be applied to samples of $\mathrm{Ti}$ and $\mathrm{Ti}$ alloys manufactured with spacers with a higher porosity degree to achieve improved performances for their use as biomaterials.

\section{Conclusions}

PEO coatings with two different $\mathrm{Ca} / \mathrm{P}$ ratios were deposited over Ti-6Al-4V alloy obtained via PM. In both cases, a homogeneous and adherent film was observed. AFM and SEM-EDS results indicated that the electrolyte modified the composition of the inner and outer layers of the coating and significantly affected the topography of the coating, resulting in a smooth, compact, and relatively less porous surface in the $\mathrm{PEO}-\mathrm{Ca} / \mathrm{P}$ coating.

The electrochemical behavior of the coated and uncoated porous $\mathrm{Ti}-6 \mathrm{Al}-4 \mathrm{~V}$ alloy was investigated in AS. The corrosion mechanisms changed owing to the application of a PEO coating, and an equivalent electric circuit was constructed to identify the mechanisms involved. The EIS spectra of the coated samples corresponded to materials in the passive state, indicating that the surface treatment yielded an efficient oxidation of the alloy even in pores that are typically difficult to passivate. A higher transfer resistance was observed in the $\mathrm{PEO}-\mathrm{Ca} / \mathrm{P}$ sample, indicating that the more compact coating reduced the possibility of electrolyte penetration and hence improved corrosion resistance. EIS measurements recorded after 90 days of immersion revealed that the $\mathrm{PEO}-\mathrm{Ca} / \mathrm{P}$ coating yielded the best corrosion performance even at long immersion time, unlike the cases of some nonporous coated samples. This is attributable to the porosity of the substrates, which improved the adherence.

Tribocorrosion tests, performed under highly aggressive conditions, showed the detachment of the anodic film on the innermost part of the samples treated with PEO. Nonetheless, the potential decrease of the coatings during sliding and the volume loss were lower than those of the noncoated sample, particularly for the PEO-Ca/P sample.

The higher rutile-to-anatase ratio and the higher Ca-to-P ratio in addition to the lower roughness, higher uniformity, and smaller grain size of the PEO-Ca/P coating resulted in more compact and harder coatings that justified their improved corrosive and tribocorrosive behaviors.

After PEO treatments, the behavior of the porous substrates improved. Hence, they are promising as an alternative material for generating $\mathrm{Ti}$ implants to be used in biomedical applications.

\section{Acknowledgements}

Financial support by Ministry of Education and Science (RTI2018-097990-B-I00) and the Junta de Castilla y Leon (VA275P18 and VA044G19) is gratefully acknowledged.

Open Access This article is licensed under a Creative Commons Attribution 4.0 International License, which permits use, sharing, adaptation, distribution and reproduction in any medium or format, as long as you give appropriate credit to the original author(s) and the source, provide a link to the Creative Commons licence, and indicate if changes were made.

The images or other third party material in this article are included in the article's Creative Commons licence, unless indicated otherwise in a credit line to 
the material. If material is not included in the article's Creative Commons licence and your intended use is not permitted by statutory regulation or exceeds the permitted use, you will need to obtain permission directly from the copyright holder.

To view a copy of this licence, visit http://creativecommons.org/licenses/by/4.0/.

\section{References}

[1] Geetha M, Singh A K, Asokamani R, Gogia A K. Ti based biomaterials, the ultimate choice for orthopaedic implants-A review. Prog Mater Sci 54(3): 397-425 (2009)

[2] Martin F, García C, Blanco Y. Influence of residual porosity on the dry and lubricated sliding wear of a powder metallurgy austenitic stainless steel. Wear 328-329: 1-7 (2015)

[3] Liu X, Chu P, Ding C. Surface modification of titanium, titanium alloys, and related materials for biomedical applications. Mater Sci Eng: R: Rep 47(3-4): 49-121 (2004)

[4] Huiskes R, Weinans H, van Rietbergen B. The relationship between stress shielding and bone resorption around total hip stems and the effects of flexible materials. Clin Orthop Relat Res (274): 124-134 (1992)

[5] Segal V M. Equal channel angular extrusion: From macromechanics to structure formation. Mater Sci Eng: A 271(1-2): 322-333 (1999)

[6] Shbeh M M, Goodall R. Open celled porous titanium. Adv Eng Mater 19(11): 1600664 (2017)

[7] Zhao Z W, Zhang G, Li H G. Preparation of calcium phosphate coating on pure titanium substrate by electrodeposition method. J Central South Univ Technol 11(2): 147-151 (2004)

[8] Thull R, Grant D. Physical and chemical vapor deposition and plasma assisted techniques for coating titanium. In Titanium in Medicine. Brunette D M, Tengvall P, Textor M, Thomsen P, Eds. Berlin: Springer, 2001: 283-341.

[9] Matykina E, Skeldon P, Thompson G E. Fundamental and practical evaluations of PEO coatings of titanium. Int Heat Treat Surf Eng 3(1-2): 45-51 (2009)

[10] Ceschini L, Lanzoni E, Martini C, Prandstraller D, Sambogna G. Comparison of dry sliding friction and wear of $\mathrm{Ti}_{6} \mathrm{Al}_{4} \mathrm{~V}$ alloy treated by plasma electrolytic oxidation and PVD coating. Wear 264(1-2): 86-95 (2008)

[11] Zhang X L, Jiang Z H, Yao Z P, Wu Z D. Electrochemical study of growth behaviour of plasma electrolytic oxidation coating on $\mathrm{Ti}_{6} \mathrm{Al}_{4} \mathrm{~V}$ : Effects of the additive. Corros Sci 52(10): 3465-3473 (2010)

[12] Martini C, Ceschini L, Tarterini F, Paillard J M, Curran J A.
PEO layers obtained from mixed aluminate-phosphate baths on Ti-6Al-4V: Dry sliding behaviour and influence of a PTFE topcoat. Wear 269(11-12): 747-756 (2010)

[13] Jin Z M, Dowson D. Bio-friction. Friction 1(2): 100-113 (2013)

[14] Matykina E, Berkani A, Skeldon P, Thompson G E. Realtime imaging of coating growth during plasma electrolytic oxidation of titanium. Electrochimica Acta 53(4): 1987-1994 (2007)

[15] Chen F, Zhou H, Chen C, Xia Y J. Study on the tribological performance of ceramic coatings on titanium alloy surfaces obtained through microarc oxidation. Prog Org Coat 64(2-3): 264-267 (2009)

[16] Yerokhin A, Parfenov E V, Matthews A. In situ impedance spectroscopy of the plasma electrolytic oxidation process for deposition of Ca- and P-containing coatings on Ti. Surf Coat Technol 301: 54-62 (2016)

[17] Shokouhfar M, Dehghanian C, Baradaran A. Preparation of ceramic coating on $\mathrm{Ti}$ substrate by plasma electrolytic oxidation in different electrolytes and evaluation of its corrosion resistance. Appl Surf Sci 257(7): 2617-2624 (2011)

[18] Park M G, Choe H C. Corrosion behaviors of bioactive element coatings on PEO-treated Ti-6Al-4V alloys. Surf Coat Technol 376: 44-51 (2019)

[19] Hussein R O, Nie X, Northwood D O. A spectroscopic and microstructural study of oxide coatings produced on a Ti-6Al-4V alloy by plasma electrolytic oxidation. Mater Chem Phys 134(1): 484-492 (2012)

[20] Laurindo C A, Torres R D, Mali S A, Gilbert J L, Soares P. Incorporation of $\mathrm{Ca}$ and $\mathrm{P}$ on anodized titanium surface: Effect of high current density. Mater Sci Eng C Mater Biol Appl 37: 223-231 (2014)

[21] Krupa D, Baszkiewicz J, Zdunek J, Smolik J, Słomka Z, Sobczak J W. Characterization of the surface layers formed on titanium by plasma electrolytic oxidation. Surf Coat Technol 205(6): 1743-1749 (2010)

[22] Hwang I J, Choe H C, Brantley W A. Electrochemical characteristics of $\mathrm{Ti}-6 \mathrm{Al}-4 \mathrm{~V}$ after plasma electrolytic oxidation in solutions containing $\mathrm{Ca}, \mathrm{P}$, and $\mathrm{Zn}$ ions. Surf Coat Technol 320: 458-466 (2017)

[23] Reshadi F, Faraji G, Baniassadi M, Tajeddini M. Surface modification of severe plastically deformed ultrafine grained pure titanium by plasma electrolytic oxidation. Surf Coat Technol 316: 113-121 (2017)

[24] Yao Z P, Jiang Y L, Jia F Z, Jiang Z H, Wang F P. Growth characteristics of plasma electrolytic oxidation ceramic coatings on Ti-6Al-4V alloy. Appl Surf Sci 254(13): 4084 4091 (2008) 
[25] Han I, Choi J H, Zhao B H, Baik H K, Lee I S. Micro-arc oxidation in various concentration of $\mathrm{KOH}$ and structural change by different cut off potential. Curr Appl Phys 7: e23-e27 (2007)

[26] Philip J T, Mathew J, Kuriachen B. Tribology of $\mathrm{Ti}_{6} \mathrm{Al}_{4} \mathrm{~V}$ : A review. Friction 7(6): 497-536 (2019)

[27] $\mathrm{Yu}$ J M, Choe H C. Morphology changes and bone formation on PEO-treated Ti-6Al-4V alloy in electrolyte containing $\mathrm{Ca}$, P, Sr, and Si ions. Appl Surf Sci 477: 121-130 (2019)

[28] Shbeh M, Yerokhin A, Goodall R. Cyclic voltammetry study of PEO processing of porous $\mathrm{Ti}$ and resulting coatings. Appl Surf Sci 439: 801-814 (2018)

[29] Menhal Shbeh M, Yerokhin A, Goodall R. Microporous titanium through metal injection moulding of coarse powder and surface modification by plasma oxidation. Appl Sci 7(1): 105 (2017)

[30] Karaji Z G, Hedayati R, Pouran B, Apachitei I, Zadpoor A A. Effects of plasma electrolytic oxidation process on the mechanical properties of additively manufactured porous biomaterials. Mater Sci Eng: C 76: 406-416 (2017)

[31] Toptan F, Alves A C, Pinto A M P, Ponthiaux P. Tribocorrosion behavior of bio-functionalized highly porous titanium. J Mech Behav Biomed Mater 69: 144-152 (2017)

[32] Mabboux F, Ponsonnet L, Morrier JJ, Jaffrezic N, Barsotti O. Surface free energy and bacterial retention to salivacoated dental implant materials: An in vitro study. Colloids Surf B Biointerfaces 39(4): 199-205 (2004)

[33] Yerokhin A L, Nie X, Leyland A, Matthews A. Characterisation of oxide films produced by plasma electrolytic oxidation of a Ti-6Al-4V alloy. Surf Coat Technol 130(2-3): 195-206 (2000)

[34] Alves S A, Bayón R, Igartua A, Saénz de Viteri V, Rocha L A. Tribocorrosion behaviour of anodic titanium oxide films produced by plasma electrolytic oxidation for dental implants. Lubr Sci 26(7-8): 500-513 (2014)

[35] de Viteri V S, Bayón R, Igartua A, Barandika G, Moreno J E, Peremarch C P J, Pérez M M. Structure, tribocorrosion and biocide characterization of $\mathrm{Ca}, \mathrm{P}$ and I containing $\mathrm{TiO}_{2}$ coatings developed by plasma electrolytic oxidation. Appl Surf Sci 367: 1-10 (2016)

[36] US-ASTM. ASTM G99-05 Standard test method for wear testing with a pin-on-disk apparatus. ASTM, 2000.

[37] Veiga C, Davim J P, Loureiro A J R. Properties and applications of titanium alloys: A brief review. Rev $A d v$ Mater Sci 32: 14-24 (2012).

[38] Rautray T R, Narayanan R, Kim K H. Ion implantation of titanium based biomaterials. Prog Mater Sci 56(8): 11371177 (2011)
[39] Yetim A F. Investigation of wear behavior of titanium oxide films, produced by anodic oxidation, on commercially pure titanium in vacuum conditions. Surf Coat Technol 205(6): 1757-1763 (2010)

[40] Suzuki K, Aoki K, Ohya K. Effects of surface roughness of titanium implants on bone remodeling activity of femur in rabbits. Bone 21(6): 507-514 (1997)

[41] de Viteri V S, Fuentes E. Titanium and titanium alloys as biomaterials. In Tribology-Fundamentals and Advancements. Rijeka, Ed. Croatia: IntechOpen, 2013: 155-181.

[42] Zhou Y L, Niinomi M, Akahori T, Fukui H, Toda H. Corrosion resistance and biocompatibility of Ti-Ta alloys for biomedical applications. Mater Sci Eng: A 398(1-2): 28-36 (2005)

[43] Myshkin N, Kovalev A. Adhesion and surface forces in polymer tribology - A review. Friction 6(2): 143-155 (2018)

[44] Pałka K, Pokrowiecki R, Krzywicka M. Porous titanium materials and applications. Titanium for Consumer Applications. Amsterdam: Elsevier, 2019: 27-75.

[45] Sasikumar Y, Karuppusamy I, Naillayan R. Surface modification methods for titanium and its alloys and their corrosion behavior in biological environment: A review. J Bio- and Tribo-Corrosion 5(36): 5-36 (2019)

[46] Aziz-Kerrzo M, Conroy K G, Fenelon A M, Farrell S T, Breslin C B. Electrochemical studies on the stability and corrosion resistance of titanium-based implant materials. Biomaterials 22(12): 1531-1539 (2001)

[47] Leitao E, Barbosa M A, De Groot K. In vitro testing of surface-modified biomaterials. J Mater Sci: Mater Med 9(9): 543-548 (1998)

[48] Pałka K, Pokrowiecki R, Krzywicka M. Porous Titanium Materials and Applications. In Titanium for Consumer Applications. Froes F, Ed. Amsterdam: Elsevier, 2019: 27-75.

[49] Vieira A C, Ribeiro A R, Rocha L A, Celis J P. Influence of $\mathrm{pH}$ and corrosion inhibitors on the tribocorrosion of titanium in artificial saliva. Wear 261(9): 994-1001 (2006)

[50] Manhabosco T M, Tamborim S M, dos Santos C B, Müller I L. Tribological, electrochemical and tribo-electrochemical characterization of bare and nitrided $\mathrm{Ti}_{6} \mathrm{Al}_{4} \mathrm{~V}$ in simulated body fluid solution. Corros Sci 53(5): 1786-1793 (2011)

[51] Khanmohammadi H, Allahkaram S R, Muñoz A I, Encinas E R, Rashidfarokhi A R. Tribocorrosion behavior of plasma electrolytic oxidation coatings on a Ti6Al4V substrate. In Proceedings of Eurocorr 2016, Montpellier, France, 2016: $1-5$.

[52] Meng Y G, Xu J, Jin Z M, Prakash B, Hu Y Z. A review of recent advances in tribology. Friction 8(2): 221-300 (2020)

[53] Ríos J M, Quintero D, Castaño J G, Echeverría F, Gómez M A. Comparison among the lubricated and unlubricated tribological behavior of coatings obtained by PEO on the 
$\mathrm{Ti}_{6} \mathrm{Al}_{4} \mathrm{~V}$ alloy in alkaline solutions. Tribol Int 128: $1-8$ (2018)

[54] Laurindo C A H, Lepienski C M, Amorim F L, Torres R D, Soares P. Mechanical and tribological properties of $\mathrm{Ca} / \mathrm{P}$-doped titanium dioxide layer produced by plasma electrolytic oxidation: Effects of applied voltage and heat treatment. Tribol Trans 61(4): 733-741 (2018)

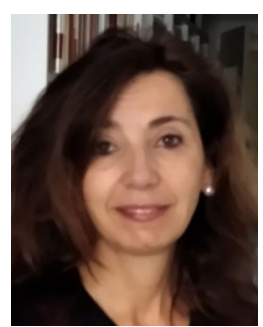

Cristina García Cabezón. She is a professor at the Engineers School of the University of Valladolid and and the co-head of the group UVASens, dedicated to the development of electrochemical sensors for the analysis of foods. She obtained a B.S.C. degree in Chemistry (U. Zaragoza, 1991) and obtained her Ph.D. degree in industrial engineering from the University of Valladolid (1998) where she is currently a professor at the Department of Materials Science.

For several years, her research was dedicated to the study of the electrochemical behavior of metals and metal nanoparticles and she became an expert in electrochemistry. Her investigation in the field of materials science and engineering is focused on corrosion, porous materials, and coatings. The materials in which these studies have been carried
[55] Kikuchi M, Takahashi M, Okuno O. Elastic moduli of cast Ti-Au, Ti-Ag, and Ti-Cu alloys. Dent Mater 22(7): 641-646 (2006)

[56] Niinomi M, Akahori T, Takeuchi T, Katsura S, Fukui H, Toda H. Mechanical properties and cyto-toxicity of new beta type titanium alloy with low melting points for dental applications. Mater Sci Eng: C 25(3): 417-425 (2005)

out are stainless steels, cobalt alloys, and titanium alloys.

In 2010, she joined the group UVASens, dedicated to the development of electrochemical sensors for the analysis of foods, where her skills in electrochemistry of metals and nanoparticles busted the research in the field of electronic tongues of the group. She has developed electrochemical sensors based on nanoparticles dedicated to the detection of antioxidants and the analysis in wines and milks. She is an author or co-author of 54 indexed articles (h-index 15). She has colaborations with several national and international groups. In particular, she is directing the collaboration with the group of Sensors of the I.P. Braganza (Portugal). She serves a referee of several journals related to electrochemistry (electrochimica acta, corrosion science, sensors, etc.). She reviews 12-15 papers per year. She regularly participates in contracts with industries. 